\title{
PRESENT TRENDS IN THE TREATMENT OF OSTEOARTHRITIS OF THE HIP \\ With an addendum for Fellowship candidates
}

\author{
By M. H. M. Harrison, Ch.M., F.R.C.S. \\ Senior Rezistrar in Orthopaedics, Westminster Hospital, London
}

The practice of orthopaedic surgery is undergoing extensive changes and the treatment of osteoarthritis of the hip reflects this in a challenging manner. Systematic surgery for this disease began to be practised on an increasing scale in the years following the first world war. An arthrodesis, once successfully achieved, was appreciated to be of great value; doubtless it was in part the difficulties and morbidity of this operation which led surgeons to work out other methods to relieve the pain of the osteoarthritic hip. So-called reconstructions of the Whitman type made a crude articulation from the distorted joint; McMurray described the use of intertrochanteric osteotomy and Girdlestone evolved the pseudarthrosis operation. These were the main procedures practised by British orthopaedic surgeons during most of the years between the wars; it was essentially salvage surgery.

Hopelessly deranged hip joints were either stiffened by arthrodesis or were refashioned or adjusted by the other relatively crude methods. Both surgeon and patient recognized that the end result fell far short of a normal hip-a painless, mobile and stable joint. Each method aimed at producing a painless joint but differed from the others in the mobility and stability that followed its performance. Considered as salvaging operations they were, and as we shall see below still are, very successful.

In the last decade another era of therapeutics for the osteoarthritic hip has been established. Two factors combined to increase both the scope of surgery and the number of patients to whom operation could be offered. Firstly, advances in anaesthesia and in transfusion techniques have made operations much safer. Secondly, much has become known about the tolerance of inert materials by the tissues of the body, and operations of prosthetic replacement have become commonplace in the treatment of osteoarthritis of the hip. Such operations aim at reconstructing a normal or near normal hip from the joint wreckage, to provide hips not only painless but stable and mobile as well-clearly different from the salvage operations.

There are two main operative techniques: In the interposition arthroplasty of Smith-Petersen a metal cup is placed between the remodelled femoral head and acetabulum, the cup is fixed to neither bone and induces a fibro-cartilaginous covering on both bone ends. In the replacement arthroplasties a portion of the upper end of the femur is resected and replaced by a prosthesis fitted into the bone. The first of such techniques to find wide application was the acrylic femoral head introduced by the Judets; seldom can an operative technique have been so widely employed in so short a time.

In deciding the best treatment for any particular patient the following points must be considered:

I. No patient is operated upon until a thorough trial of physiotherapy has been given, and if necessary repeated, without obtaining satisfactory relief from pain.

2. The great majority of operations are performed to relieve severe and disabling pain, a much smaller number to correct deformity. Accordingly it is essential to estimate how much pain the patient suffers and what inroads it makes into his life.

3. The surgeon explains to the patient the level of functional activity likely to follow operation; the patient can then see how this will fit in with his needs at work and at home.

4. The lumbar spine, the other hip and the knees are examined; the findings may indicate whether the affected hip can be stiffened or must be left mobile.

5. A general physical examination determines whether the patient can stand a major hip operation. An assessment of the patient's emotional make up is important when considering arthroplasty as this operation requires considerable cooperation throughout a long post-operative course of physiotherapy.

The final decision regarding operation is made with reference to these five points and to the preference of surgeon and patient. The techniques now in common use will be briefly discussed. 


\section{Arthrodesis}

Although arthrodesis destroys the joint, success depends upon obtaining bony union between femur and acetabulum; this requires considerable skill. Osteogenesis is hindered by the long lever of the lower limb which tends to disturb the junctional tissues at the slightest movement. Intra-articular arthrodesis is the method of choice and most surgeons reinforce this by metallic internal fixation, by a bone graft or by both. The disadvantages of arthrodesis are the difficulty of securing bony ankylosis, the duration of plaster immobilization which is relatively ill tolerated by older patients and the risk of stiffening the knee by such immobilization. Even a partially stiff and painful knee is serious in the presence of an arthrodesed hip, and new techniques are still being devised to overcome these difficulties. The functional result of an arthrodesis is excellent and this operation finds its greatest application in the unilateral osteoarthritic hip of the youngish patient. The hip is completely stable and painless, excellent for walking and standing, less well adapted to sitting. The optimum position of ankylosis of the adult hip is neutral rotation, flexion $25^{\circ}$ and

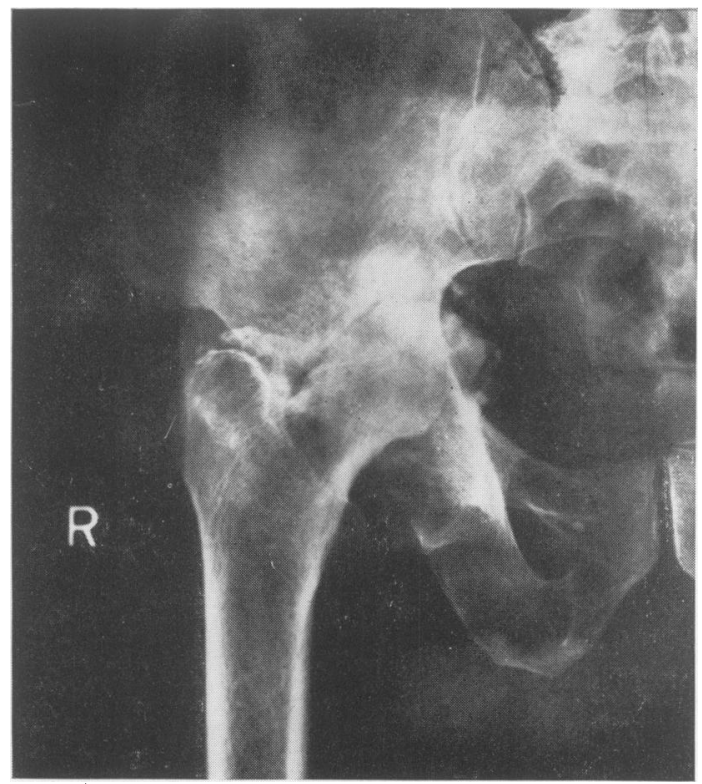

Fig. 1.-Central dislocation arthrodesis (Mr. J. Charnley's case). The hip having been widely dislocated the femoral head and neck are cut to the form of a cylinder and pushed through a hole made in the acetabular floor. The medial end of the reshaped head now lies within the true pelvis. A metal clamp, not shown here, which compresses the great trochanter to the ilium is buried in the wound in those cases where bony ankylosis is sought; the clamp is removed after six weeks. abduction only to compensate for any rea shortening.

Charnley (1953) has approached the problem of hip arthrodesis in a new fashion. His central dis location technique either produces an arthrodesis? of the hip (Fig. I) or results in a fibrous ankylosie allowing $10^{\circ}$ to $30^{\circ}$ of flexion, but without move ment in other directions. This desirable state of affairs prevents a Trendelenberg gait and is due to the central dislocation creating a bone block tof lateral and rotary motion. The procedure hasmany impressive features; in Charnley's hands if appears technically straightforward, is not shock $\vec{\omega}$ ing, fixes the knee post-operatively for only one month, all plaster is discarded at six weeks an $\mathbb{B}$ the patient leaves hospital in about a furthere fortnight. The author was recently privileged to see a follow-up review of $3 \circ$ patients who had beenim operated during the last six years; the degree of freedom from pain and the high level of functionatw activity of the group as a whole was most impressive.

\section{Resection of the Femoral Head and Neck? the Pseudarthrosis Operation}

This is neither a difficult nor a shocking pro $-\frac{5}{-1}$ cedure and is well tolerated by the reasonably give patient of 70 years (Fig. 2). It was practised atdor taught by G. R. Girdlestone, whose technique a do results are described by Taylor (1950). The opera tion results in a mobile hip, a short leg ( $1 \frac{1}{2}$ in.) and․ㅡㅇ a limp due to a positive Trendelenberg; the

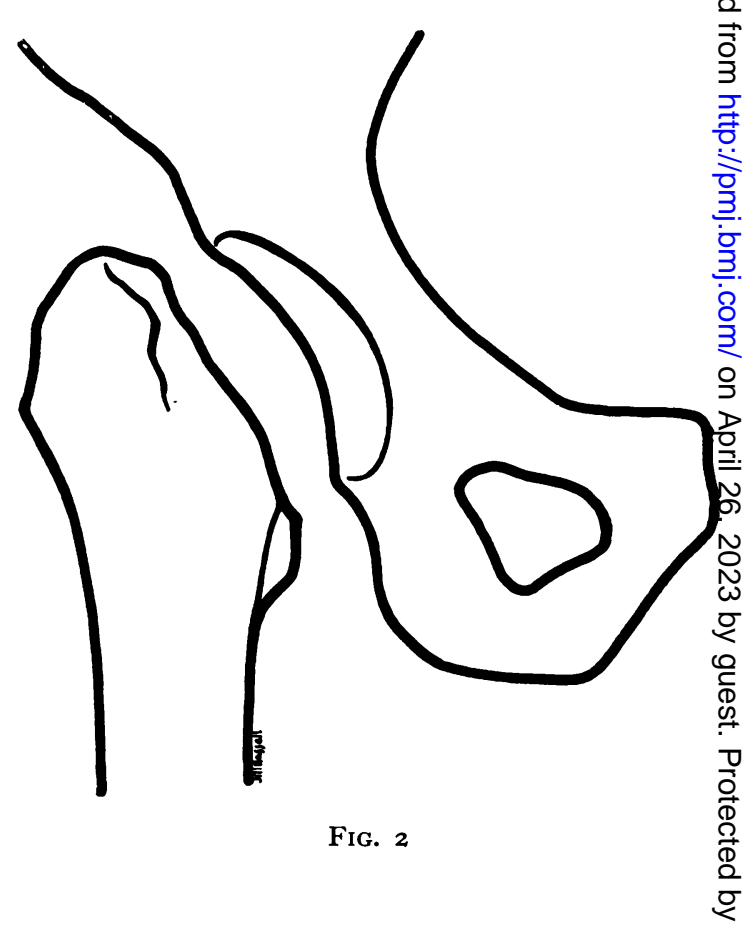


majority but not all the patients thus have permanent need of a stick. It is effective in relieving pain and younger patients have been enabled to walk long distances, drive a tractor, etc., after its performance. Patients sit very well after this operation; it can be performed bilaterally. The procedure is very useful for the older patient and those cases where it is obligatory not only to relieve pain but to leave a mobile hip. Batchelor (1940) has added an abduction osteotomy to the original procedure in an attempt to increase the stability.

\section{Intertrochanteric Femoral Osteotomy}

This was first performed for osteoarthritis of the hip by McMurray (1939), who aimed to displace the distal fragment medially beneath the acetabulum (Fig. 3). It is a straightforward and simple operation which aims to relieve pain and correct deformity; the range of motion in the hip is not increased. As originally performed the operation had the same disadvantages of immobilization as arthrodesis, but now some surgeons are using internal fixation to obviate this. As the popularity of acrylic arthroplasty wanes osteotomy is being increasingly performed in many centres; a most interesting fact which has become apparent is that pain relief does not seem to depend upon the maintenance of displacement at the osteotomy site

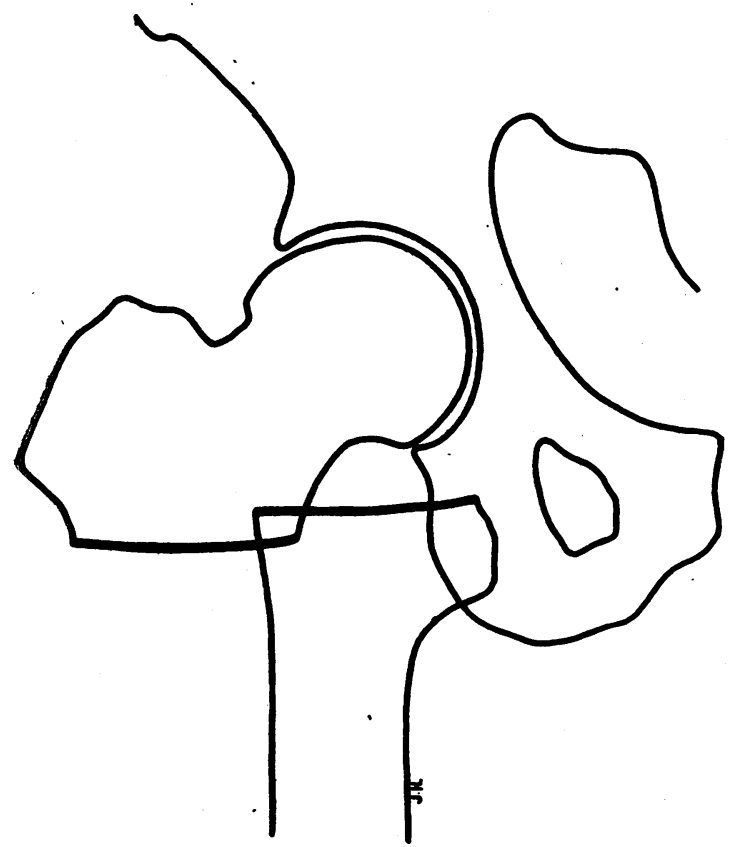

FIG. 3.-A tracing of a radiograph showing the displacement that has been obtained after intertrochanteric osteotomy; the femoral fragments unite in this position. -equally satisfactory results have been obtaine after osteotomies in which the bone fragments appear to have returned to their original position?

\section{Arthroplasty}

One problem is common to both types of arthro plasty, the method of approach. Both the anteriof (Smith-Petersen) and the posterior (Gibson क. approaches and their modifications are used ex tensively, neither enjoys an overwhelming superi $\frac{0}{0}$ ority over the other. In reconstruction of a hip it? is necessary to preserve normal gluteus medius action to prevent a Trendelenberg gait, and to maintain the tension in the short rotator musclesw and thus maintain stability. New operative approaches are still being devised in an attempt to ensure these desirable happenings (McFarland an Osborne, 1954).

Cup arthroplasty entails a thorough exposure of the hip joint, remodelling of both femoral heaf and acetabulum and, finally, the insertion of vitallium cup which covers the femoral head and fits into the acetabulum. The technique of Smith = Petersen (1939) has remained largely unmodified $\vec{\longrightarrow}$ Adams (1953) has recently introduced the con centric cup which aims to provide a betteres mechanical arrangement within the new joint; the long-term results must be awaited with interest $s$

The original replacement arthroplasty utilizedr the Judet acrylic prosthesis (Judet, J. and R.,, $\mathcal{B}$ al., I954), and this is the one which has been thes most popular in this country. The hip is dis- $-\overline{0}$ located, the femoral head is resected and the acetabulum is remodelled. The prosthesis is then inserted by driving its stem into a channel prepared in the length of the femoral neck.

If the acrylic femoral head had an enthusiastic reception, it has equally had extensive modification. Between 1950 and 1953 it largely supplanted the cup but the popularity of replacement arthro-3. plasty is now very seriously threatened. Innumer-able alterations have been made since the prototype 3 . was introduced; they take two chief forms. The constitution of the prosthesis is varied whereby different materials are used either singly or ino combination. More significant, however, is the changing shape of the prosthesis-the overallo change is towards the use of bigger prostheses entailing resection of more of the original articulationo (Fig. 4). Thus some of those who are exploring 0 the possibilities of this type of surgery are replac-N ing the whole of the femoral head and neck by $a_{\sigma}$ prosthesis whose fixation has extended from the original $2 \frac{1}{2}$ in. stem of the Judet prosthesis to ac medullary nail which goes almost halfway down@ the femoral shaft. The prosthetic joint has already been used in the knee and the elbow and is beingo contemplated for the hip! 

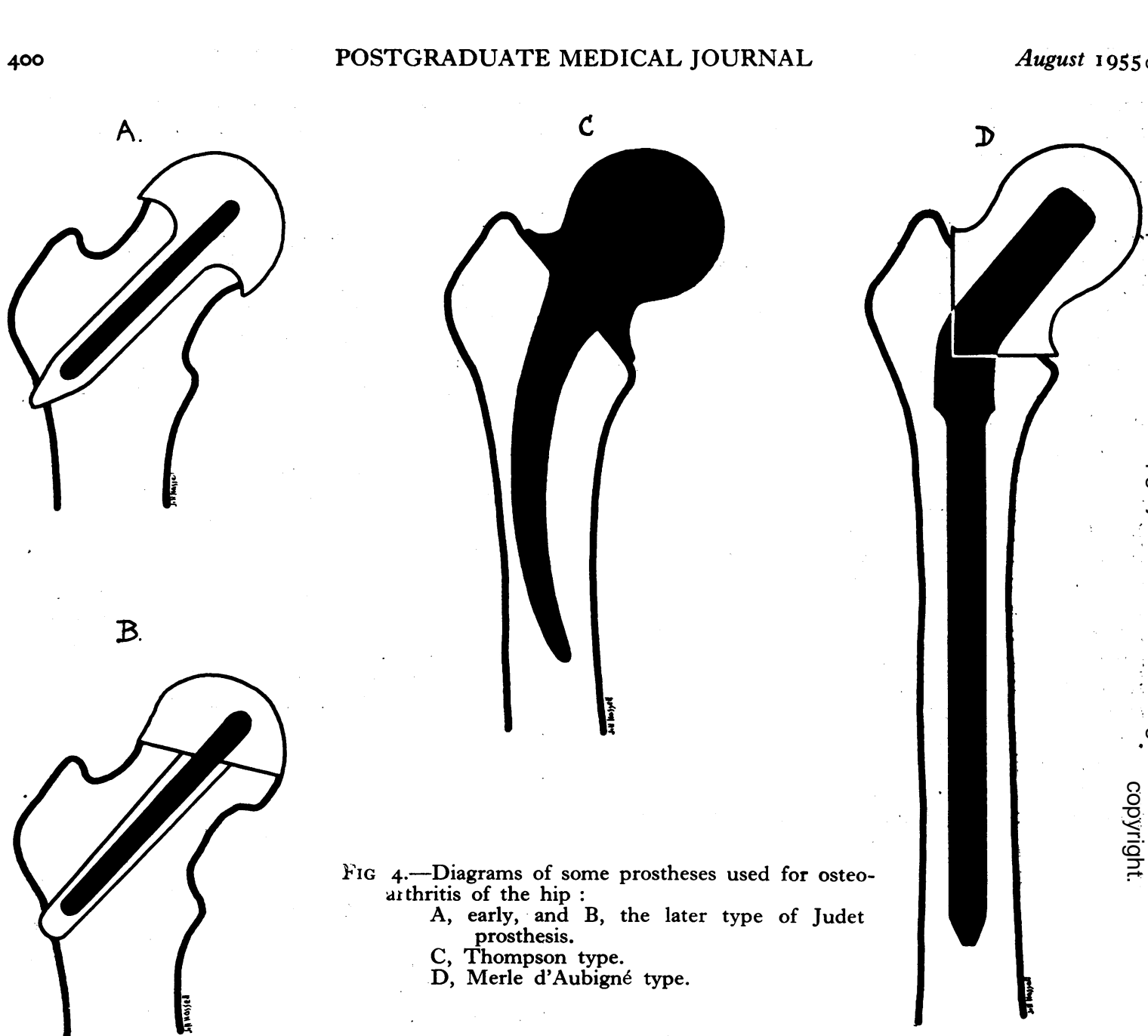

Fig 4.-Diagrams of some prostheses used for osteo-

$A$, early, and $B$, the later type of Judet

C, Thompson type.

D, Merle d'Aubigné type. arthritis of the hip : prosthesis.

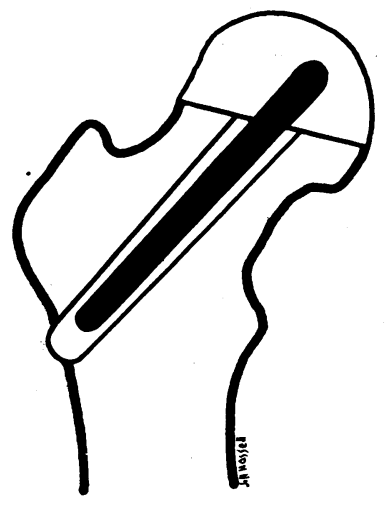

These changes reflect both the disappointments and the hopes of those engaged in this phase of orthopaedic surgery. The results of replacement arthroplasty have disappointed a majority of surgeons who had hoped so much from it, and this disappointment is being met by some who are trying to find the way whereby the occasional excellent result may be achieved in large numbers.

Replacement arthroplasty may fail due to:

I. The use of materials which fracture, deform or produce tissue reaction.

2. Post-operative subluxation or dislocation of the new joint. It is not difficult to insert an acrylic head into a femoral neck, but it is difficult to place it in a predetermined position after having removed just the right amount of bone from the joint to leave a fit which is neither too loose nor too tight.

3. Dislocation is prevented by skilled surgery and nursing; late loosening of the prosthesis is probably only in part dependent upon the tech- nique of operation. The evolution of prostheses which replace more and more of the upper end of the femur and whose fixation extends progressively down the shaft is one way whereby this problem of late loosening of the prosthesis is being attacked. These rather formidable looking appliances areprobably receiving a slow and cautious application in the traditionally conservative schools of British orthopaedics.

The commonest cause of disappointment after arthroplasty is the onset of pain and stiffness in the $N$ reconstructed joint. This is in part connected with the problems just discussed, but will be considered again below.

In summary, the arthroplasties require the greatest surgical skill of all operations on the osteoarthritic hip if they are to be successful. They require prolonged post-operative physiotherapy; the early results are frequently very en- $\frac{0}{0}$ couraging, the late results are not infrequently $\frac{\vec{\Phi}}{\infty}$ disappointing. While the two-year follow up re- $\frac{\stackrel{O}{\overparen{D}}}{\stackrel{O}{O}}$ 

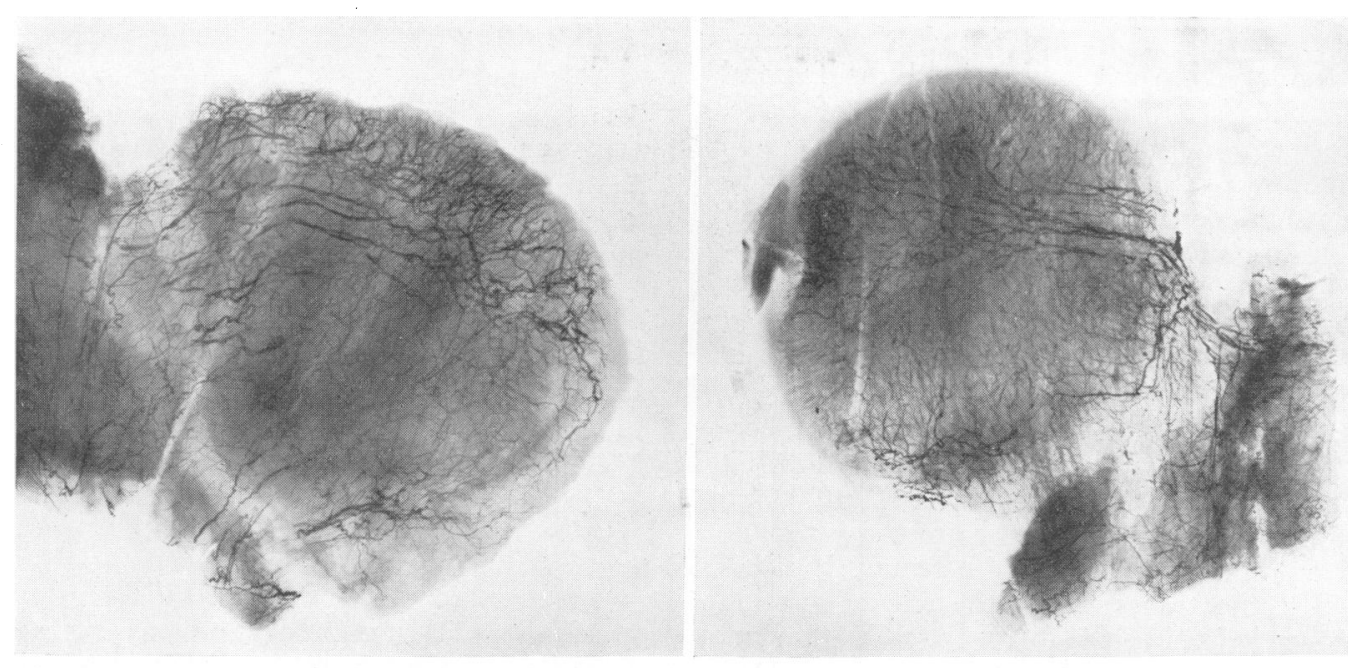

A

FIG. 5.-Arteriograms, obtained postmortem, of the femoral heads of a subject aged 76 . The right, A, is the site of advanced osteoarthritis. The left, B, is essentially normal. The arteries within the osteoarthritic head are seen to be dilated and increased in number. (Reproduction by kind permission of the Editor of the Fournal of Bone and Foint Surgery.)

view is of interest, it is the five to ten year result which is of significance.

\section{Comment}

The difficulties and disappointments of the orthopaedic surgeon and his patient assume a correct perspective when viewed against certain facts. Osteoarthritis is a painful disease, surgery aims to relieve the pain and yet we are completely ignorant of the origin of this symptom. Perhaps the capsule, synovium and the bone all contribute, but to say more is speculation. This is less surprising when one remembers that very little is known of the nerve supply of bone.

We can only guess at the factors controlling the resorption and production of bone, how then should we prevent the loosening of prostheses or new bone formation around reconstructed joints?

It is well recognized that certain methods employed in physiotherapy relieve joint pain. Heat in one form or another is very often effective, yet what is known of the mode of action of the justly popular short wave diathermy? Recent work has suggested that as usually applied its heating effect is largely confined to the superficial tissues (Scott, I955), and that whereas it produces an increased circulation in the skin the blood flow in deeper organs may be decreased (in the kidney, Kottke et al., 1949; in muscle, Harris, 1955). It is interesting to compare this last piece of evidence with the findings that the vascular tree within the osteoarthritic femoral head is grossly abnormal, being in a condition of widespread arterial hyperaemia and venous dilatation (Fig. 5) (Harrison,
Schajowicz and Trueta, I953). It seems possible that at least some of the pain of this disease might have a vascular basis and Trueta is af present exploring the possibilities of relieving the pain of osteoarthritis by local intraosseous $\mathrm{X}=$ irradiation. The finding of this deranged vascular bed perhaps throws some light on the successes which have been known for a long time occasionally to follow external $\mathrm{X}$-irradiation in this disease.

In the light of these deficiencies in knowledge our attempt to build new joints by arthroplasty can be compared to the attempted construction of a bridge designed to carry heavy traffic without intimate knowledge of the principles of engineering and mechanics. Small wonder that the result is unpredictable.

It is fascinating to speculate on the difficulties and the future of arthroplasty. The problem of the reconstruction of a durable joint after the resection of an osteoarthritic one is a biological problem, mechanical solutions must be biologically acceptable. There are at least two major difficulties to be considered.

Firstly, evidence has been offered elsewhere for the thesis that osteoarthritis represents the response of the tissues of a joint to unfavourable mechanical circumstances (Harrison, Schajowicz and Trueta, I953). If this is correct, then even granted a perfect prosthesis, what is to prevent the re-appearance of osteoarthritic lesions in the living tissues adjacent to the prosthesis, if it merely substitutes a portion of the diseased joint and leaves the original abnormal anatomy and mechanics un- 
changed? Such lesions are found after arthroplasty both in the acetabulum and the femoral neck stump (sclerosis and eburnation of bone, cyst formation and osteophytes) and may well account for a return of symptoms. Operations which would correct the underlying anatomy in addition to joint reconstruction might be considered by many to be altogether too formidable.

Secondly, there arises the problem of a method of durable and perfect fixation of an inert material to living bone. It is precisely here that orthopaedic surgery differs from carpentry and engineering. Great forces are transmitted by the hip but the tissues of the normal joint successfully stand up to them. However securely a prosthesis may be bolted or otherwise fixed to the femur, it seems likely that the trabeculae at the site of fixation cannot survive unless the forces to which they are exposed can be kept down to something like those normally prevailing. It may very well be that such can never be obtained in this, the most major weight bearing joint in the body. Scales (1954) is attempting to overcome these difficulties by using metal plate fixation only as a temporary measure contriving finally to secure the shaft of the prosthesis by new bone formation.

Cup arthroplasty should theoretically be successful in osteoarthritis secondary to a local deformity of femoral head or acetabulum which can be corrected at the time of operation (viz., old Perthe's disease, slipped epiphysis, malunion of intraarticular fractures, congenital subluxation of the hip). For the reasons just advanced replacement arthroplasty may prove unsuccessful in these conditions, as may both forms of arthroplasty in osteoarthritis due to anatomical defects occurring at an extra-articular level-old congenital dislocation, coxa vara and valga, anteversion of the femoral neck. In such patients, arthrodesis, osteotomy or pseudarthrosis may still provide the greatest percentage of satisfying results.

The follow-up studies of De Vas (1954) and Shepherd (1954) lend some support to these beliefs in that they show the results of cup arthroplasty to be more durable than those of replacement. What would be most interesting, however, would be to compare the results of cup arthroplasty in the different aetiological groups just mentioned, i.e. intra-articular causes and 'pathology at a distance.'

The most worthwhile approach to the problem of osteoarthritis of the hip is that of prophylaxis. Increasing skill in the treatment of dislocation and other congenital deformities of the hip, of Perthe's disease and slipped epiphysis in the first two decades, will reduce the incidence of clinical osteoarthritis in the adult.

\section{Addendum}

If a candidate in a higher surgical examination has been given $I_{5}$ to 20 minutes to examine $\Rightarrow$ patient with an osteoarthritic hip he should face his examiners armed with the following informgtion:

I. How is the affected hip or hips troubling the patient? What inroads is it making into his life? Does it disturb sleep, necessitate analgesiçs, affect employment, cause him to use a stick? fs there any history of bone disease or injury in earlier years which might be of aetiological significance $\frac{\dot{d} \overline{d n}}{g}$ the present arthritis?

2. Clinical examination should yield:

(a) The degree of any fixed deformity of the affected hip-most osteoarthritic hips lie in $\overrightarrow{\mathrm{ca}^{\mathrm{a}}}$ position of flexion, adduction and external rotetion. The examinee will be familiar with Thomas' test for flexion deformities of the hro.

(b) The amount of any real or apparent shortening. The examinee should be able to discuss the reasons for any differences in the measurements. If there is any real shortenifing it will be necessary to determine in which sef ment of the lower limb this is occurring. g g be first step in such elucidation is to cons Bryant's triangles which will reveal any shodeit ing occurring above the trochanteric region of the femur. Should Bryant's triangles be equal dimensions on both sides, the cause gf $^{\mathrm{f}}$ any real shortening must be sought for mofe distally than the hip joints.

(c) The range of motion in the affected hi $\overrightarrow{\vec{\beta}}$, considering flexion, abduction, adduction, medial and lateral rotation and extension in turn. T T cardinal physical signs of an arthritis is the limitation of motion in the affected joint to 3 n approximately equal extent in all three planes.

(d) The presence of wasting of the thigh.

(e) Is Trendelenberg's sign positive or nega tive?

(f) An estimate of the mobility of the lumbror spine and the joints in both lower limbs.
(g) It is a useful precaution to conclude examination by eliciting the ankle and pupillof reflexes; a Charcot joint may be painful in its early stages of development but will allow \&్తn abnormal range of movement.

\section{Acknowledgments}

I would like to express my thanks both to Maps J. Hassell for her drawings and to the Photography Department of the Westminster Hospital.

Bibliography continued on page $4 \mathrm{I} 3$ 


\section{Prognosis}

While the immediate results of resection in acute regional colitis appear to be good, few cases have been reported and none has had a long follow up. In the case reported here and the one described by Thompson (personal communication) there has been no evidence of recurrence after four and five years respectively. In chronic regional colitis, recurrence following excision or short circuiting is unfortunately by no means uncommon. Neuman et al. (1954), record a recurrence rate of 37 per cent. after surgical procedures but they point out that their figures are based on a small number of cases and that the follow up has been short in most. Relapse after a long interval of apparent cure is not unknown and Butler (1953) records a case in which this occurred after eight years.

\section{Summary}

A case of regional colitis, which first presented as an acute abdominal emergency, is reported. Following a caecostomy the affected segment of bowel rapidly stenosed and was subsequently resected. A four year follow-up shows no evidence of recurrence.

The literature is reviewed and the pathology and treatment are discussed.

I wish to thank Mr. J. A. McLauchlan, under whose care the patient was admitted, for permis- sion to publish this case; Dr. T. Culoty for the radiological reports; and Dr. L. Steingold for the pathological report.

I am indebted to Dr. Lynne Reid and the Photographic Department of the Brompton Hospital for the photomicrography.

\section{BIBLIOGRAPHY}

ARMITAGE, G., and WILSON, M. (1950), Brit. F. Surg., 38, 182. BARBOSA, J. DE C., BARGEN, J. A., and DIXON, C. F. (1945), Surg. Clin. N. Amer., 25, 939.

BARGEN, I A. (1943), 'The Modern Management of Colitis,' C. C.'Thomas, Springfield, Ill.

BARGEN, J. A., and WEBER, H. M. (1930), Surg. Gyn. Obst., 50, 964 .

BROWNLEE, T. J. (195I), Brit. F. Surg., 38, 507

BUTLER, E. C. B. (1953), Proc. Roy. Soc. Med., 46, 69.

CORBETT, R. S. (1945), Ibid., 38, 277.

CROHN, B. B., and BERG, A. A. (1938), F. Amer. med. Ass., I10, 32.

CROHN, B. B., GARLOCK, J. H., and YARNIS, H. (1947), Ibid., 134, 334 .

CROHN, B. B., GINSBERG, L., and OPPENHEIMER, G. D. (I932), Ibid., 99, 1323.

CROHN, B. B., and ROSENAK, B. B. (1936), Ibid., 136, I.

DALZIEL, T. K. (1913), Brit. med. F., i, 425.

LUMB, G. (1951), Brit. F. Surg., 39, 233.

MOSCHOWITZ, E., and WILENSKY, A. G. (1923), Amer. F. med. Sci., 166, 48 .

MOYNIHAN, B. G. A. (1907), Edin. med. f., 21, 228.

NEUMAN, H. W., BARGEN, J. A., and JUDD, E. S. (1954), Surg. Gyn. Obst., 99, 563.

NEUMAN, H. W., and DOCKERTY, M. B. (1954), Ibid., 9 572.

ROBSON, A. W. MAYO (1908), Brit. med. F., i, 425.

THOMPSON, H. R. (1950), Proc. Roy. Soc. Med., 43, 685.

TIETZE, A. (1920), Erg. Chir. Orthop., 12, 211.

WELLS, C. (1952), Ann. Roy. Coll. Surg. Eng., II, 105.

\section{NOTICE OF SPECIAL INTEREST TO SUBSCRIBERS:}

"WHY NOT HAVE YOUR COPIES OF THIS JOURNAL BOUND INTO YEARLY VOLUMES?"

Arrangements have now been made to have the twelve monthly issues fully bound in dark green pin head cloth, lettered in gilt on spine with name of Journal, Volume Number and year, complete with index at front, 17s. 6d. per Volume, post free. A limited number of out of print journals are available to bind into volumes and make your library complete. Price on application giving details of issues required to complete back volumes.

THE FELLOWSHIP OF POSTGRADUATE MEDICINE 60 PORTLAND PLACE, LONDON, W.I

\section{WHY NOT HAVE YOUR JOURNALS BOUND?}

Bibliography continued from page 402-M. H. M. Harrison, Ch.M., F.R.C.S.

\section{BIBLIOGRAPHY}

ADAMS, J. C. (1953), f. Bone ft. Surg., 35B, 199.

BATCHELOR, J. S. (1948), Postgrad. med. F., 24, 24 I.

CHARNLEY, J. (1953), 'Compression Arthrodesis.' E. and S. Livingstone, London.

DEVAS, M. S. (1954), f. Bone ft. Surg., 36B, 561.

HARRIS, R. (1955), Personal communication.

HARRISON, M. H. M., SCHAJOWICZ, F., and TRUETA, J(1953), $\mathfrak{f}$. Bone $\dot{f}_{t}$. Surg., 35B, 598.

JUDET, J., JUDET, R., LAGRANGE, J., and DUNOYER, I (I954), "Resection-reconstruction of the hip; arthroplasty with an acrylic prosthesis."
KOTTKE, F. J., KOZA, D. W., KUBICEK, W. G., and OLSON, M. (1949), Arch. phys. med., 30, 431.

McFARLAND, B., and OSBORNE, G. (1954), f. Bone ft. Surg., 36B, 364 .

McMURRAY, T. P. (1939), f. Bone $\mathfrak{f t}$. Surg., 21, I.

SCALES, J. (1954), Personal communication.

SCOTT, B. O. (1955), Personal Communication.

SHEPHERD, M. M. (7954), f. Bone ft. Surg., 36B, 567.

SMITH-PETERSEN, M. N. (1939), F. Bone ft. Surg., 21, 269.

TAYLOR, R. G. (1950), f. Bone ft. Surg., 32B, I6r. 